\title{
Article \\ Acute Responses of Core Muscle Activity during Bridge Exercises on the Floor vs. the Suspension System
}

\author{
Jim T. C. Luk ${ }^{1, *}$, Freeman K. C. Kwok ${ }^{1}$, Indy M. K. Ho ${ }^{1}\left(\mathbb{D}\right.$ and Del P. Wong ${ }^{2,3}$ \\ 1 Department of Sports and Recreation, Technological and Higher Education Institute of Hong Kong (THEi), \\ Hong Kong; freemankkc@gmail.com (F.K.C.K.); indyho@thei.edu.hk (I.M.K.H.) \\ 2 School of Nursing and Health Studies, The Open University of Hong Kong, Hong Kong; \\ delwong.cuhk@gmail.com \\ 3 Titi Sports Technology, Shenzhen 518000, China \\ * Correspondence: jim_luk@thei.edu.hk; Tel.: +852-3890-8248; Fax: +852-3890-8330
}

Citation: Luk, J.T.C.; Kwok, F.K.C.; Ho, I.M.K.; Wong, D.P. Acute Responses of Core Muscle Activity during Bridge Exercises on the Floor vs. the Suspension System. Int. J. Environ. Res. Public Health 2021, 18, 5908. https://doi.org/10.3390/ ijerph18115908

Academic Editor: Paul B. Tchounwou

Received: 27 April 2021

Accepted: 25 May 2021

Published: 31 May 2021

Publisher's Note: MDPI stays neutral with regard to jurisdictional claims in published maps and institutional affiliations.

Copyright: (c) 2021 by the authors. Licensee MDPI, Basel, Switzerland. This article is an open access article distributed under the terms and conditions of the Creative Commons Attribution (CC BY) license (https:// creativecommons.org/licenses/by/ $4.0 /$ )

\begin{abstract}
This study aimed to compare the neuromuscular activation of selected core musculature in supine and prone bridge exercises under stable versus suspended conditions. Forty-three healthy male participants were recruited to measure the electromyographic activities of the rectus abdominis (RA), lumbar multifidus (LM), thoracic erector spinae (TES), rectus femoris (RF), gluteus maximus $(\mathrm{GM})$, and biceps femoris (BF) during supine and prone bridge exercises under six conditions: control, both arms and feet on the floor $\left(\right.$ Prone $_{\text {con }}$ and Supine con $_{\text {) }}$; arms on the floor and feet on

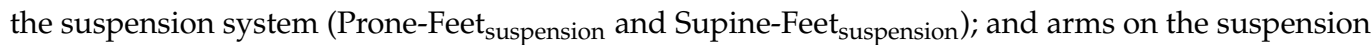
system and feet on the floor (Prone-Arm suspension $_{\text {and Supine-Arm }}$ suspension). Prone-Arm suspension $_{\text {S }}$ yielded significantly higher activities in the RA, RF, TES, and LM than Prone-Feet suspension $(p<0.01)$

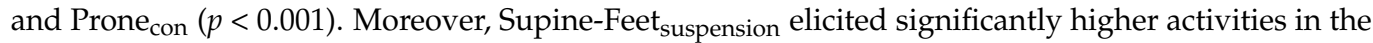
RA, RF, TES, LM, and BF than Supine-Arm suspension $(p<0.01)$ and Supine con $(p<0.001)$. Furthermore, Supine-Feet suspension $_{\text {elicited significantly higher activities in the RF, TES, and BF than Supine }}$ con $(p<0.01)$. Therefore, if the RA and/or RF were the target training muscles, then Prone-Arm suspension was recommended. However, if the TES, LM, and/or BF were the target training muscles, then Supine-Feet suspension $_{\text {was recommended. }}$
\end{abstract}

Keywords: surface EMG; prone bridge; supine bridge; unstable surface; plank

\section{Introduction}

In recent years, the importance of core stability and strength is widely recognized in rehabilitation and athletic training [1]. The core muscles serve as the center of the functional kinetic chain, contribute to resistance against spinal perturbations [2], and transfer power to the terminal segments in athletic activities [3]. In the rehabilitative field, core-strengthening exercises can decrease the risk of injuries by increasing muscle power and endurance [4]. A meta-analysis reveals that core stability exercises are better than general exercises in decreasing pain and restoring physical functions in patients with chronic lower back pain [5]. Another previous study has found that the training of trunk-stabilizing muscles plays an important role in preventing lower extremity injuries in the athletic population [6], which has a direct impact on the mobility of limbs [7] and performance-related fitness [8,9].

Typical strengthening exercises for core muscles include supine bridge, prone bridge, and crunch exercises [10]. Performing exercises on unstable surfaces may be more effective than performing on stable surfaces in increasing the somatosensory feedback and enabling continuous adjustment of the overall position [11]. Common destabilizing strategies include the use of swiss balls, BOSU balls, and suspension straps. In particular, previous studies have found that performing dynamic resistance exercises on unstable surfaces generally reduce the peak force, rate of force development, and agonist muscle activity compared with performing on stable surfaces [12]. In contrary to dynamic exercises, 
performing static isometric exercises on unstable surfaces increases the muscle activity of trunk-stabilizing muscles. Previous studies have found that performing prone bridge exercises on a swiss ball or with hands on suspension straps results in higher muscle activity in the rectus abdominis (RA) compared with performing the same exercise on the floor $[11,13]$. Likewise, performing prone and supine bridges on a whole-body vibration platform induces higher trunk muscle activity compared with performing the same exercise on the floor [14]. However, research on the muscle activity during prone bridge exercises with feet on the suspension straps is limited [15], although previous studies have reported the use of suspension training in athletic populations, such as synchronized swimming [16] and Chinese boxing [17], and in clinical patients with brain injury [18] and functional training in older adults [19].

During suspension training, the participant usually suspends from the handles of the straps by either their hands or feet, while the non-suspended pair of extremities is in contact with the ground [20]. A recent systematic review has found that previous studies of suspension training exercises primarily focus on dynamic exercises (such as push-ups, inverted row, and hamstring curl) and static exercises (such as prone bridge) [21]. Most of the studies only focus on the core muscle activities during supine bridge exercises [22] or prone bridge-related exercises $[2,11,15,23,24]$, but a direct comparison between supine and prone bridges with and without the use of a suspension system is still lacking. In addition, literature comparing the muscle activities between prone and supine bridges performed using a suspension system on arms versus floor exercises [20] or using a swiss ball as an unstable surface [25] is limited. The comparison of muscle activities between stable and unstable surfaces is better with similar posture and trunk inclination; however, most of the literature compares the exercises with very different trunk inclination because of the use of swiss balls or improper length of suspension straps [11,26,27]. Moreover, to date, no study has directly investigated the muscle activity when performing the two common static core muscle training exercises (i.e., prone and supine bridges), particularly when either the hands or feet are on the suspension straps.

Therefore, this study aimed to compare the neuromuscular activation of selected core musculature in supine and prone bridge exercises under stable versus unstable (i.e., suspension system) conditions. This study provided empirical evidence for trainers and therapists to make an informed decision when selecting between the two bridge exercises (i.e., prone and supine bridges) in three different forms to maximize training effectiveness.

\section{Materials and Methods}

\subsection{Experimental Approach to the Problem}

Within-participant repeated-measure design was used to compare the muscle activities under six conditions: control, both arms and feet on the floor (Prone ${ }_{\text {con }}$ and Supine $_{\text {con }}$ ); arms on the floor and feet on the suspension system (Prone-Feet ${ }_{\text {suspension }}$ and Supine-Feet suspension$_{\text {); }}$ and arms on the suspension system and feet on the floor (Prone-

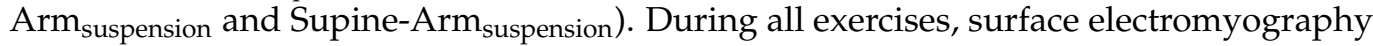
(sEMG) of the rectus abdominis (RA), lumbar multifidus (LM), thoracic erector spinae (TES), rectus femoris (RF), gluteus maximus (GM), and biceps femoris (BF) was measured. Exercise sequence was counterbalanced. EMG data were normalized with maximal voluntary contraction (MVC) values before being used for comparison among different exercise conditions.

\subsection{Participants}

Forty-three healthy male subjects (age: $21.40 \pm 1.78$ years; height: $174.74 \pm 7.68 \mathrm{~cm}$; mass: $64.42 \pm 8.25 \mathrm{~kg}$; body fat: $10.94 \% \pm 3.20 \%$, abdominal skinfold thickness: $12.11 \pm 5.31 \mathrm{~mm}$ ) volunteered for this study after providing a written informed consent and Physical Activity Readiness Questionnaire. The inclusion criteria for participants were as follows: (1) no history of lower back pain for more than 6 weeks before the study, (2) no surgery or trauma of the abdominal/back area requiring stitches within the last 12 months, (3) no 
lumbopelvic pain during an active straight leg raise test, (4) no muscle pain or discomfort when performing the selected exercises in this study, (5) with previous experience or background of training with suspension system and (6) abdominal skinfold measurement less than $25 \mathrm{~mm}$ and body fat less than $24 \%$ because percentages greater than this cut-off increased impedance of the EMG signal $[28,29]$. On the day of testing, participants reported having abstained from caffeine and vigorous exercise in the previous $12 \mathrm{~h}$. This study was approved by the Research Ethics Committee of the Technology and Higher Educational Institution (Reference No: THEi-ILO/5/1/8) and in accordance with the Declaration of Helsinki [30].

\subsection{Procedures}

Each subject completed the anthropometric measures and screening protocol conducted by a registered physiotherapist. Prior to electrode placement, each subject performed a 5 min ergometer warm-up, and the subjects were familiarized with the exercise requirements to ensure that they could perform all selected exercises using a proper form.

Bipolar silver/silver-chloride electrodes (Ambu BlueSensor T, Ambu, Copenhagen, Denmark) with an inter-electrode distance of $30 \mathrm{~mm}$ were applied to bilateral RA, LM, TES, RF, GM, and BF and aligned with the pennate muscles on the bellies. Placements of electrodes for the RA [10], LM [31], TES [31], RF [32], GM [33], and BF [34] were reported in previous studies. The skin preparation and identification of electrode locations were performed following the procedure from the literature [33].

The MVC of each muscle was measured in different body positions as reported in previous studies: RA [35], RF [36], LM, TES, GM, and BF [37]. Three trials of $5 \mathrm{~s}$ MVC were performed for each muscle with at least $50 \mathrm{~s}$ of rest between trials [10]. The middle $3 \mathrm{~s}$ averaged root mean square (RMS) was collected. The greatest RMS among the three MVC trials was used to normalize each of the corresponding muscle activities in the subsequent tests, which allowed inter-individual comparison with the individual maximum [38].

Upon completion of MVC exercises, the six bridge exercises were performed in a counterbalanced order. Each variation of the bridge exercises was held for a $30 \mathrm{~s}$ isometric contraction and was repeated for two trials with a 5 min rest interval. The averaged RMS of the electrical muscle activities from the 12.5th to the 17.5th second was collected. The arms of the subjects were kept constantly perpendicular to ground level in prone bridge conditions to ensure internal consistency of the technique, whereas $90^{\circ}$ knee flexion was maintained in supine bridge conditions (Figures 1 and 2). The suspension system (TRX, Fitness Anywhere, Inc., San Francisco, CA, USA) was anchored to a metal frame at $4 \mathrm{~m}$ from the ceiling. Handles were placed approximately $6-8 \mathrm{~cm}$ above the ground for ProneFeet $_{\text {suspension, }}$ Prone-Arm suspension, $_{\text {, and Supine-Feet }}$ suspension. The length of the suspension

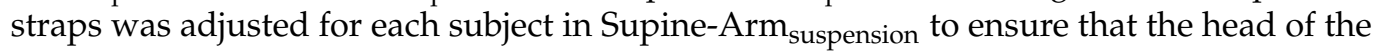
subject was approximately $6-8 \mathrm{~cm}$ above the ground.

The proper techniques of each exercise were as follows: regular prone bridge (Prone con $_{\text {) }}$ ) is a prone bridge position on an exercise mat with arms held perpendicular to ground level. Only the palms and toes were in contact with the ground. Subjects were instructed to maintain a neutral head and spine with extended leg position throughout the exercise

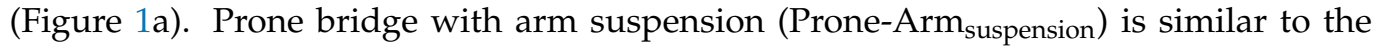
regular prone bridge position with feet placed together on the ground, while the hands were placed inside the suspension straps with a neutral grip position and straight-arm position perpendicular to ground level (Figure 1b). Prone bridge with feet on a suspension

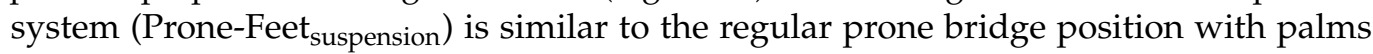
on the ground, while the instep was placed on the suspension straps (Figure 1c). Regular supine bridge (Supine ${ }_{\text {con }}$ ) is a supine bridge position with feet shoulder-width apart. Arms were placed beside the torso, and the knees were flexed at $90^{\circ}$ with both feet resting on the exercise mat. The pelvis was lifted and aligned with the thigh (Figure 2a). Supine bridge

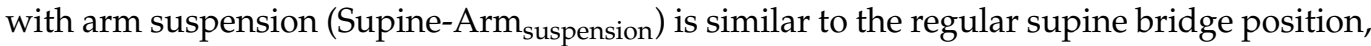
but the suspension handle was held in a neutral grip position and straight-arm position 
perpendicular to ground level (Figure $2 b$ ). The supine bridge with feet on a suspension

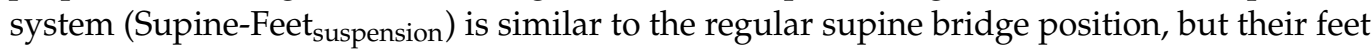
were placed onto the suspension strap shoulder width apart (Figure 2c).

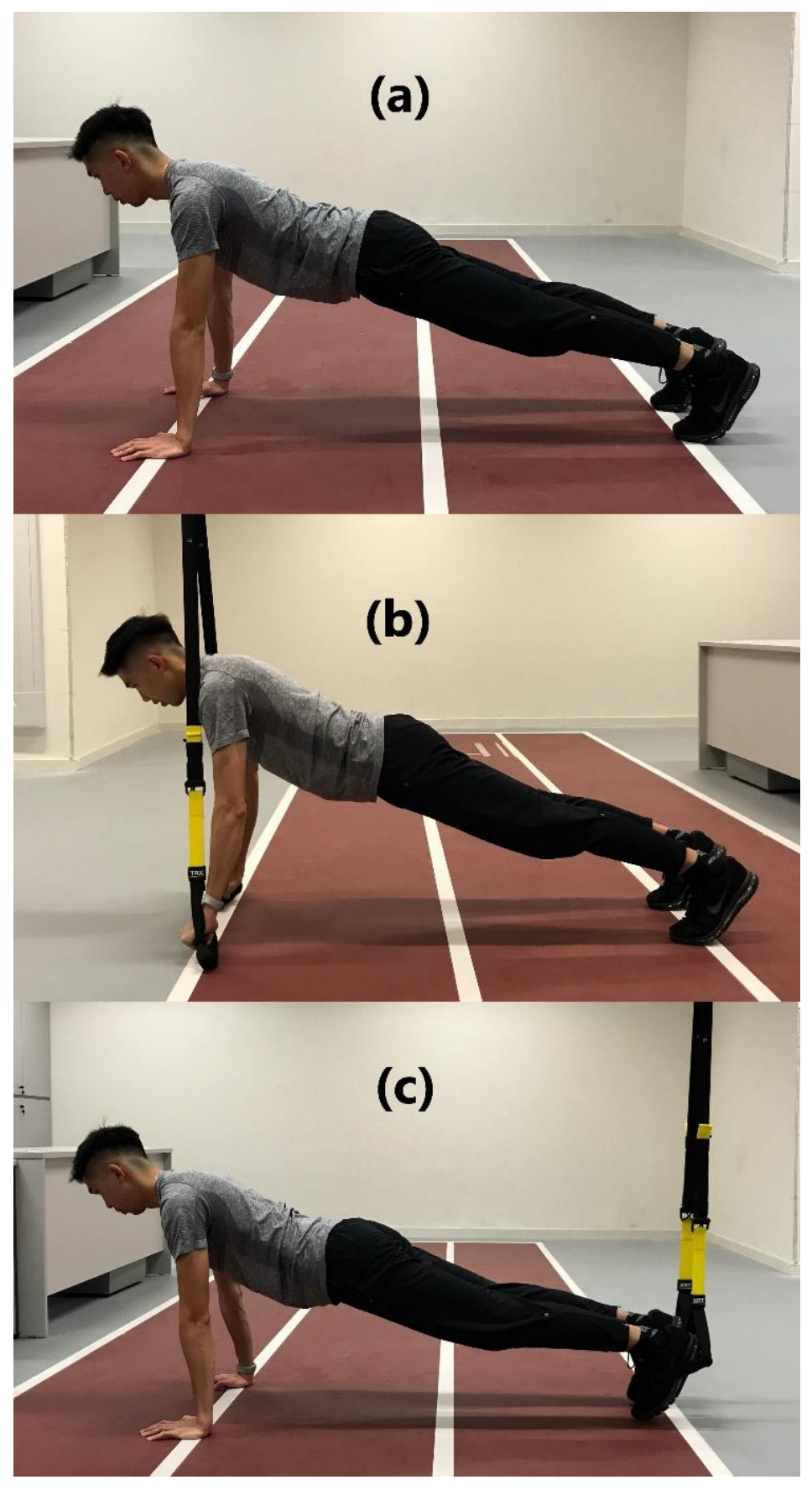

Figure 1. (a) Regular prone bridge (Prone ${ }_{\text {con }}$ ) is a prone bridge position on an exercise mat with arms held perpendicular to ground level. Only the palms and toes were in contact with the ground. Subjects were instructed to maintain a neutral head and spine with extended leg position throughout

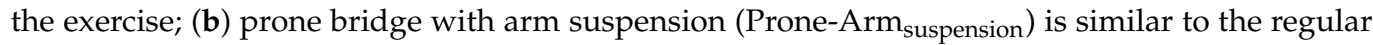
prone bridge position with the feet placed together on the ground, while the arms were placed inside the suspension straps with a neutral grip position and straight-arm position perpendicular to ground

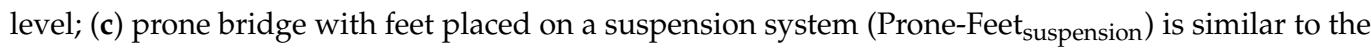
regular prone bridge position with palms placed on the ground, while the instep was placed on the suspension straps. 


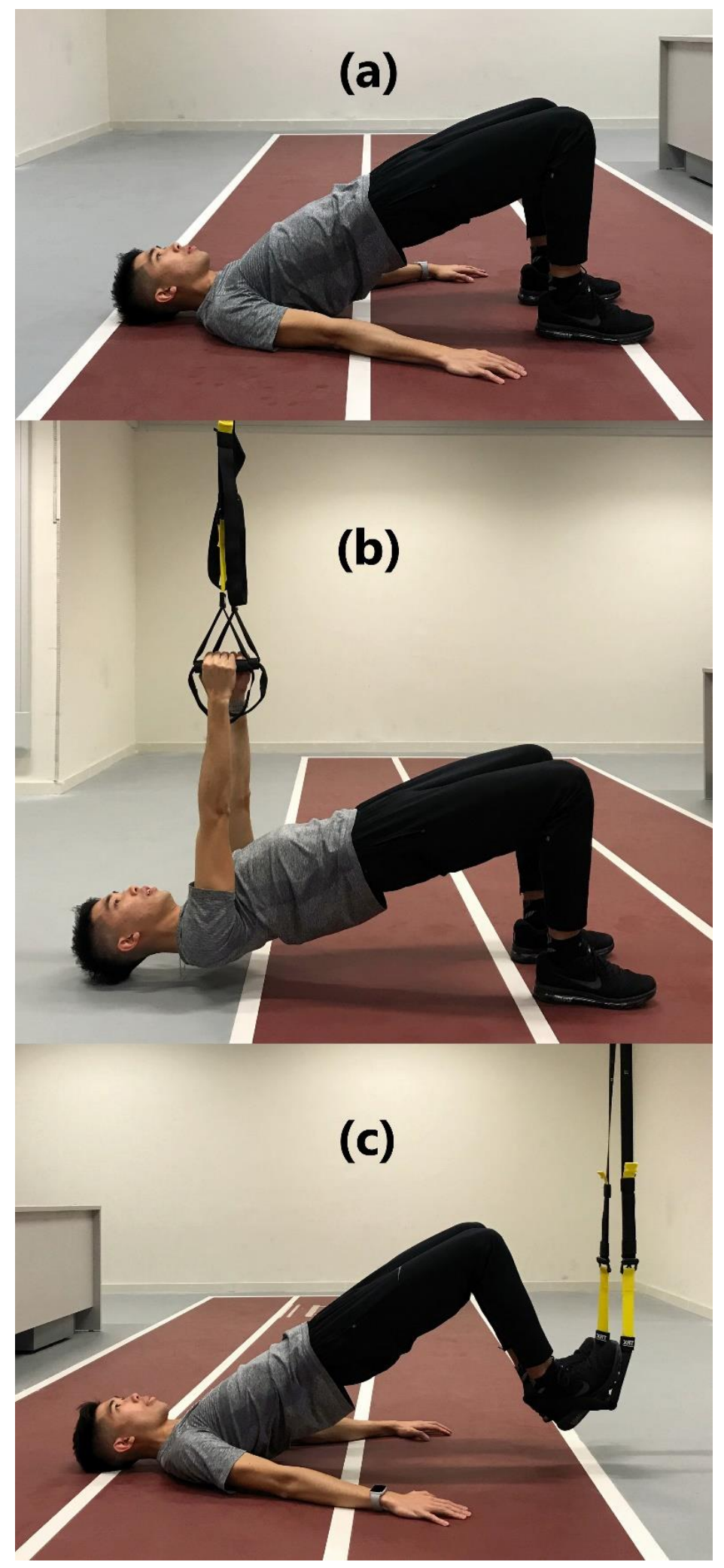

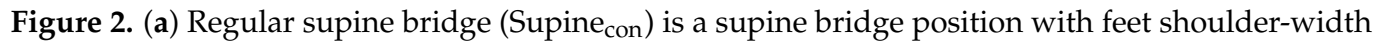
apart. The arms were placed beside the torso, and the knees were flexed at $90^{\circ}$ with both feet resting on the exercise mat. The pelvis was lifted and aligned with the thigh; (b) supine bridge with arm

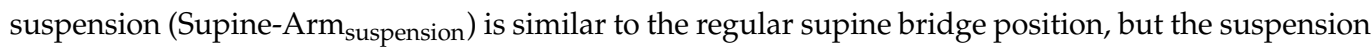
handle was held in a neutral grip position and straight-arm position being perpendicular to ground

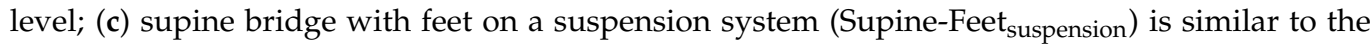
regular supine bridge position, but the feet were placed onto the suspension strap in shoulder width. 
sEMG was measured at a sampling rate of $1500 \mathrm{~Hz}$ using a 12-channel data logger allied to the wireless TeleMyo Desktop Direst Transmission System (Noraxon, Inc., Arizona, USA). All collected signals were subsequently band-pass filtered between 10 and $500 \mathrm{~Hz}$ and then rectified and smoothed by calculating the RMS with a $50 \mathrm{~ms}$ sliding window. In MVC, the greatest RMS calculated from each trial of each side was averaged into one value to represent the muscle group bilaterally. In the six exercises, the greatest RMS calculated from each trial of each side was averaged and normalized, which was expressed as \%MVC. The four levels of \%MVC developed in previous studies were adopted to compare the muscle activation level among different conditions, with $<21 \%$ as low, $21-40 \%$ as moderate, $41-60 \%$ as high, and $>60 \%$ as very high $[4,39]$.

\subsection{Statistical Analysis}

Data were reported as means and SD values. An intraclass correlation coefficient (ICC) with absolute agreement was used to determine the same-day test-retest reliability of sEMG recordings [40]. The classification of ICC values was as follows: $<0.50$ poor reliability, $0.50-0.75$ moderate reliability, $0.76-0.90$ good reliability, and $>0.90$ excellent reliability [41]. One-way repeated-measure analysis of variance was conducted to determine the global difference in sEMG activity among the six conditions. Post hoc pairwise comparisons with Bonferroni corrections were used. Statistical significance was set at $\alpha=0.05$. Cohen's $d$ effect size (ES) values were also determined with the following cut-off values: $<0.40$ small, $0.40-0.70$ moderate, and $>0.7$ large [42].

\section{Results}

Table 1 shows the test-retest reliability of EMG measurements between the two repeated trials. Among the 36 sets of reliabilities, 8, 24, and 4 had excellent, good, and moderate ICC reliabilities, respectively.

Table 1. Test-retest reliability of sEMG recordings (after MVC normalization) within the same day.

\begin{tabular}{|c|c|c|c|c|c|c|}
\hline Variations & Prone $_{\text {con }}$ & Prone-Feet $_{\text {suspension }}$ & Prone-Arm ${ }_{\text {suspension }}$ & Supine $_{\text {con }}$ & Supine-Feet $_{\text {suspension }}$ & Supine-Arm $_{\text {suspension }}$ \\
\hline RA & 0.8 & 0.81 & 0.97 & 0.84 & 0.94 & 0.91 \\
\hline RF & 0.87 & 0.85 & 0.9 & 0.86 & 0.9 & 0.87 \\
\hline TES & 0.9 & 0.75 & 0.91 & 0.94 & 0.89 & 0.88 \\
\hline LM & 0.89 & 0.8 & 0.69 & 0.88 & 0.92 & 0.77 \\
\hline GM & 0.82 & 0.56 & 0.75 & 0.81 & 0.89 & 0.92 \\
\hline $\mathrm{BF}$ & 0.93 & 0.87 & 0.8 & 0.81 & 0.9 & 0.86 \\
\hline
\end{tabular}

Note: Values are intraclass correlation coefficient (ICC). 0.50-0.75: moderate reliability, orange 0.76-0.90: good reliability, light green $>0.90$ : excellent reliability, dark green. Rectus abdominis (RA), rectus femoris (RF), thoracic erector spinae (TES), lumbar multifidus (LM), gluteus

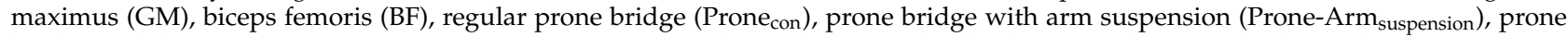

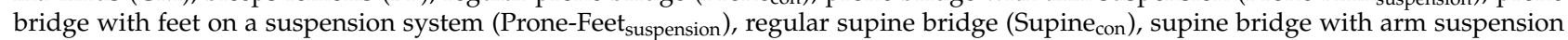
(Supine-Arm suspension $)$, and supine bridge with feet on a suspension system (Supine-Feet suspension$_{\text {). }}$.

Significant differences were found among the three conditions of prone exercises in the RA ( $F=118.9, p<0.001$; Table 2 and Figure 3$)$, RF $(\mathrm{F}=153.8, p<0.001)$, TES $(\mathrm{F}=258.2$, $p<0.001), \mathrm{LM}(\mathrm{F}=251.0, p<0.001), \mathrm{GM}(\mathrm{F}=128.8, p<0.010)$, and $\mathrm{BF}(\mathrm{F}=172.9, p<0.001)$. The post hoc results indicated that Prone-Arm suspension yielded significantly higher activities in the RA, RF, TES, and LM as compared with Prone-Feet suspension $(p<0.010$, all large ES: $\mathrm{RA}=3.64, \mathrm{RF}=1.01, \mathrm{TES}=1.30$, and $\mathrm{LM}=1.71)$ and Prone con $(p<0.001$, all large ES:

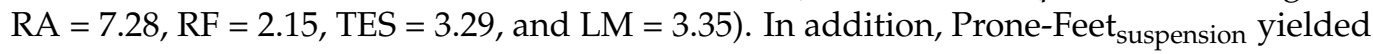
significantly higher activities in the RA, RF, TES, and LM as compared with Prone con $_{\text {n }}$ $(p<0.001$, all large ES: RA $=1.42, \mathrm{RF}=0.78, \mathrm{TES}=1.26$, and $\mathrm{LM}=1.00)$. Post hoc and ES

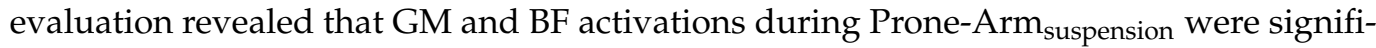
cantly greater than those during Prone ${ }_{\mathrm{con}}(p<0.010, \mathrm{ES}: \mathrm{GM}=0.53$ and $\mathrm{BF}=0.98)$. 
Table 2. Muscle activity (\%MVC) during isometric bridge exercises under six different conditions.

\begin{tabular}{|c|c|c|c|c|c|c|c|c|c|c|c|c|}
\hline \multirow{2}{*}{ Muscle } & \multicolumn{2}{|c|}{ Prone $_{\text {con }}$} & \multicolumn{2}{|c|}{ Prone-Feet $_{\text {suspension }}$} & \multicolumn{2}{|c|}{ Prone-Arm ${ }_{\text {suspension }}$} & \multicolumn{2}{|c|}{ Supine $_{\text {con }}$} & \multicolumn{2}{|c|}{ Supine-Feet $_{\text {suspension }}$} & \multicolumn{2}{|c|}{ Supine-Arm suspension } \\
\hline & Mean \pm SD & $95 \% \mathrm{CI}$ & Mean \pm SD & $95 \% \mathrm{CI}$ & Mean \pm SD & $95 \% \mathrm{CI}$ & Mean \pm SD & $95 \% \mathrm{CI}$ & Mean \pm SD & $95 \% \mathrm{CI}$ & Mean \pm SD & $95 \% \mathrm{CI}$ \\
\hline RA \# & $26.9 \pm 15.1$ & $22.3,31.6$ & $48.3 \pm 24.3$ & $40.8,55.7$ & $136.7 \pm 77.7$ & $\begin{array}{l}112.8 \\
160.6\end{array}$ & $2.2 \pm 1.8$ & $1.6,2.7$ & $4.3 \pm 4.2$ & $3.0,5.6$ & $2.4 \pm 1.3$ & $2.0,2.7$ \\
\hline $\mathrm{RF}^{*}$ & $19.9 \pm 9.5$ & $17.0,22.8$ & $27.2 \pm 12.9$ & $23.2,31.2$ & $40.2 \pm 20.1$ & $34.0,46.4$ & $2.0 \pm 1.1$ & $1.7,2.4$ & $3.2 \pm 1.8$ & $2.6,3.7$ & $2.3 \pm 1.3$ & $1.9,2.7$ \\
\hline TES * & $4.2 \pm 1.5$ & $3.8,4.7$ & $6.2 \pm 2.4$ & $5.4,6.9$ & $9.3 \pm 4.7$ & $7.9,10.7$ & $34.8 \pm 14.1$ & $30.4,39.1$ & $49.3 \pm 16.7$ & $44.2,54.5$ & $38.7 \pm 13.6$ & $34.5,42.9$ \\
\hline $\mathrm{LM}^{*}$ & $3.6 \pm 1.9$ & $3.0,4.2$ & $5.5 \pm 2.6$ & $4.7,6.3$ & $9.9 \pm 5.0$ & $8.4,11.5$ & $45.3 \pm 18.3$ & $39.7,51.0$ & $53.6 \pm 19.6$ & $47.6,59.6$ & $46.7 \pm 15.9$ & $41.8,51.6$ \\
\hline GM \&^\# & $1.9 \pm 2.7$ & $1.1,2.7$ & $2.6 \pm 3.0$ & $1.7,3.6$ & $3.3 \pm 1.6$ & $2.9,3.8$ & $21.7 \pm 7.3$ & $19.5,24.0$ & $12.9 \pm 6.7$ & $10.8,14.9$ & $20.0 \pm 9.6$ & $17.0,23.0$ \\
\hline $\mathrm{BF}^{\wedge}$ & $3.6 \pm 2.8$ & $2.7,4.4$ & $5.4 \pm 4.3$ & $4.0,6.7$ & $6.3 \pm 4.0$ & $5.1,7.6$ & $21.4 \pm 13.2$ & $17.3,25.5$ & $64.3 \pm 27.2$ & $56.0,72.7$ & $27.8 \pm 14.1$ & $23.4,32.1$ \\
\hline
\end{tabular}

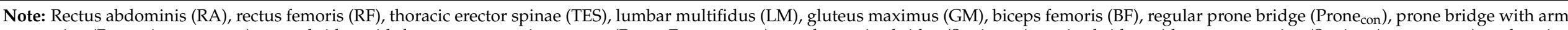

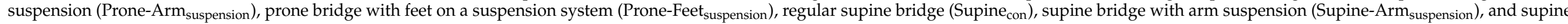

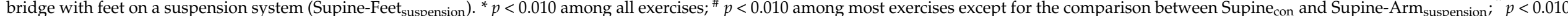

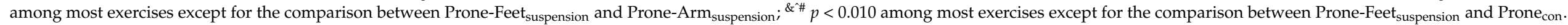




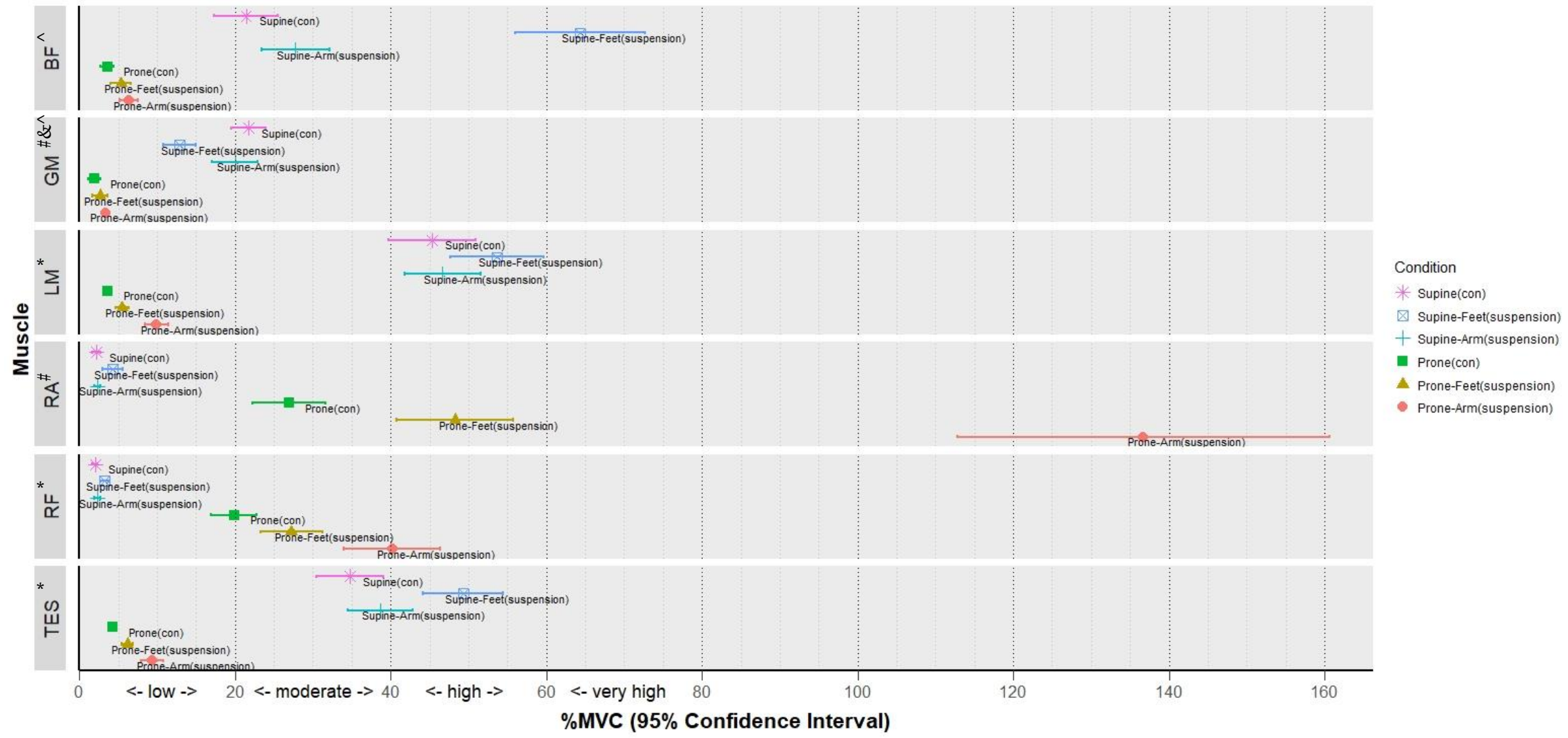

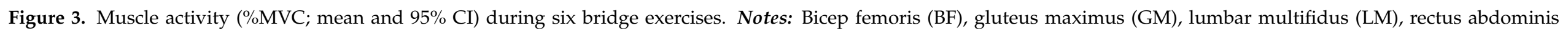

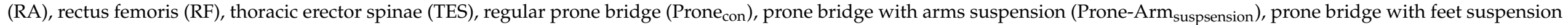

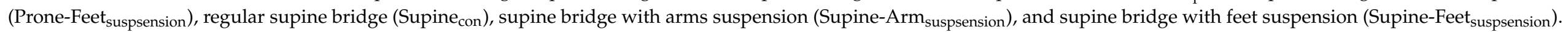

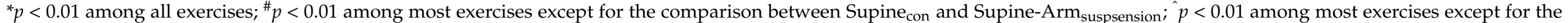
comparison between Prone-Feet suspsension $_{\text {and Prone-Arm }}$ suspsension $_{i}{ }^{\star \wedge} p<0.01$ among most exercises except comparison between Prone-Feet suspsension $_{\text {and Prone }}$ con. 
Regarding the three supine conditions, significantly different muscle activations were found among the three conditions for all muscles (Table 2 and Figure 3): RA ( $F=118.9$, $p<0.001), \mathrm{RF}(\mathrm{F}=153.8, p<0.001)$, TES $(\mathrm{F}=258.2, p<0.001), \mathrm{LM}(\mathrm{F}=251.0, p<0.001), \mathrm{GM}$ $(\mathrm{F}=128.8, p<0.010)$, and $\mathrm{BF}(\mathrm{F}=172.9, p<0.001)$. Post hoc analysis revealed that SupineFeet $_{\text {suspension }}$ elicited higher muscle activities in the RA, RF, TES, LM, and BF as compared with Supine-Arm suspension $(p<0.010, \mathrm{ES}: \mathrm{RA}=1.46, \mathrm{RF}=0.69, \mathrm{TES}=0.78, \mathrm{LM}=0.43$, and $\mathrm{BF}=2.59)$ and Supine ${ }_{\mathrm{con}}(p<0.001, \mathrm{ES}: \mathrm{RA}=1.17, \mathrm{RF}=1.08, \mathrm{TES}=1.03, \mathrm{LM}=0.45$, and $\mathrm{BF}=3.25)$. Activations of the RF, TES, and $\mathrm{BF}$ were also significantly higher during Supine-Arm suspension in comparison with Supine $_{\text {con }}(p<0.010, \mathrm{ES}$ : RF $=0.27, \mathrm{TES}=0.28$,

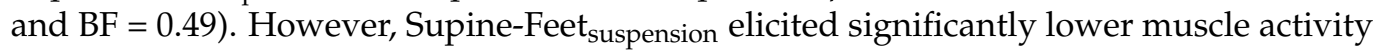
for the GM when compared with Supine-Arm suspension $_{(}(p<0.001, \mathrm{ES}=1.06)$ and Supine $\mathrm{e}_{\mathrm{con}}$ $(p<0.001, \mathrm{ES}=1.31)$.

\section{Discussion}

This study aimed to compare the neuromuscular activation of the selected core musculature in supine and prone bridge exercises under stable versus unstable (i.e., suspension system) conditions. The results of this study indicated that the instability provided by the suspension system increased the activation levels of core musculatures, such as the RA, LM, TES, RF, and BF, during static exercises, such as supine and prone bridges. This study was the first to show that the use of suspension training increased muscle activation as compared with conventional supine/prone bridge exercises performed on a stable surface. In particular, a high level of activations of the anterior musculature (i.e., RA) in prone bridge and posterior musculature (i.e., TES, LM, and BF) in supine bridge was observed.

Although TES, LM, GM, and BF remained in the low activation level in prone bridge exercises in this study, they demonstrated a significant difference in muscle activities across different exercise conditions. The result was congruent to that of the previous study,

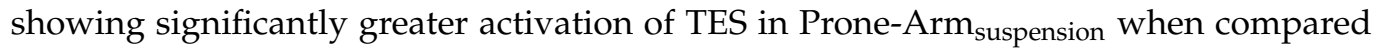

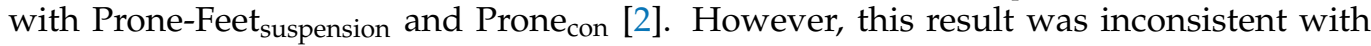
that of a previous study showing no difference in the activation of TES and GM when performing the prone bridge exercise with and without foot suspension [20]. Nonetheless, prone bridge exercises should not be considered as effective training for TES, LM, GM, and BF because of the low activation level of these muscles.

The current results showed that the highest muscle activities of the RA and RF were found in Prone-Arm suspension, followed by Prone-Feet $_{\text {suspension }}$ and Prone con $_{\text {(Figure 3). }}$. This result was consistent with that of previous studies showing that the activation level

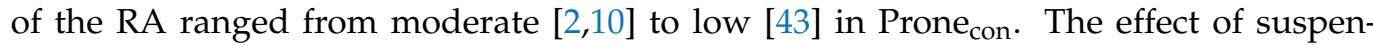
sion training on RA activation in our study was consistent with that of the previous similar studies. Previous studies indicated a 33\% increase in RA muscle activation with

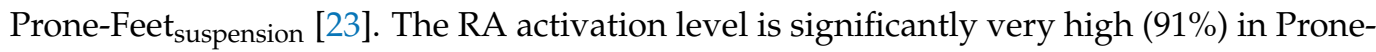
Arm $_{\text {suspension, }}$ high (55\%) in Prone-Feet suspension, $_{\text {, and moderate (36\%) in Prone }}$ con [2]. Furthermore, a significant increase in the muscle activation of the RA, RF, and TES was found when push-up was performed on a suspension training system [22]. Based on the findings of the present study, moderate muscle activation, moderate-to-high-level muscle activation, and high-to-very-high muscle activation of the RA and RF could be achieved in Prone con, $_{\text {, }}$ Prone-Feet $_{\text {suspension, }}$ and Prone-Arm suspension, $_{\text {, respectively. }}$

In supine bridge exercises, the anterior muscles (RA and RF) remained in the low activation level, whereas their muscle activities were significantly higher in Supine-Feet suspension $_{\text {sin }}$

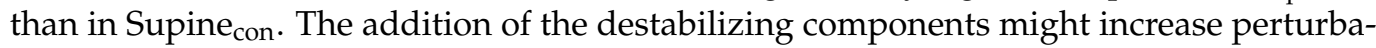
tion of the trunk. Thus, the demand of coactivation of the global and local core musculature was increased to produce comparable counterforces to offset the rotational torque and maintain the same pelvic level on both sides. Significantly higher activation of the BF was observed in Feet suspension than in Supine $_{\text {con }}$. Considering that the long head of BF muscle was attached to the ischial tuberosity, which was responsible for posterior pelvic rotation, high demand of RA and RF for generating the torque in the opposite direction 
was required to counteract any undesirable posterior pelvic rotation induced by the BF. When comparing our results regarding the RA activity in supine bridge conditions with those of recent studies, conflicting findings were observed. One of the studies revealed that RA activation was significantly higher in Supine-Feet suspension $_{\text {than in }}$ Supine $_{\text {con }}$ [20]. On the contrary, another finding indicated that RA activation remained unchanged between foot-suspended and stable conditions [22]. Our findings are congruent with the former results. Subjects performed supine bridge exercises in the study conducted by Calatayud et al. (2017) using a suspension system with straps differently designed, which required participants to place the sole of their feet flat on the strap. Consequently, the researchers hypothesized that the biomechanical characteristics between Supine-Feet suspension $_{\text {and }}$ Supine $_{\text {con }}$ exercises were similar. However, the suspension straps used in the current study and in the study conducted by Harris et al. (2017) required subjects to anchor their heels on the straps. With this setting, the researchers hypothesized that high forward sliding moment potentially increased the isometric works on the BF directly and the RA indirectly for stabilization purposes.

Regarding the activation of the GM in our study, the significant decrease of its activities

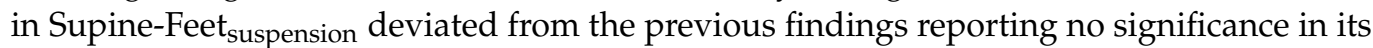

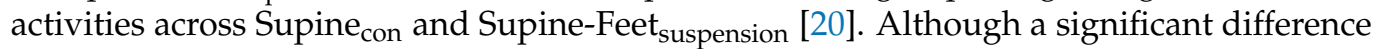
in GM activity was observed among supine bridge exercises in this study, only moderate activity level was found in Supine con $_{\text {and Supine-Arm }}$ suspension. The supine bridge exercises only induced the moderate muscle activity level on the GM.

The lumbopelvic complex played an important role in transferring forces through body segments and kinetic chains. The \%MVC was determined by the ratio between the resistance and muscle mass [44]. During bridge exercises, the contributing ratio between the upper and lower anterior musculature (RA and RF) and posterior musculature (TES, $\mathrm{LM}$, and $\mathrm{BF}$ ) in the lumbopelvic complex changed along the shift of the center of mass under different suspension conditions and the adjustment of the direction of force exerted on body segments because of the change of relative body position on the base of support. Supine-

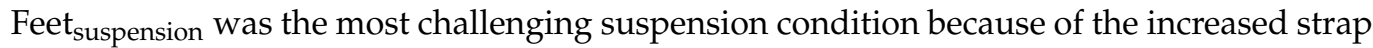
pulling force on knee extension. Maintaining the body form under this body position required an intense sustained knee flexion, which could be demonstrated by the very high activation level of the BF in this study. This finding also indicated the high activation level of TES and LM in stabilizing the pelvis to boost the efficiency of force transmission through

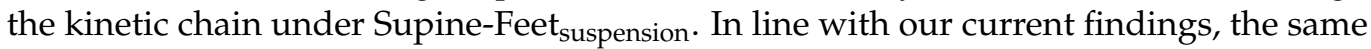

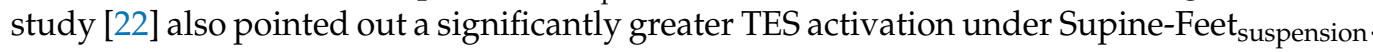
Therefore, Supine-Feet $t_{\text {suspension }}$ is a good option when compared with Supine con $_{\text {and }}$

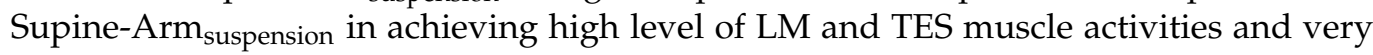
high level of BF muscle activity.

The rectified and smoothed EMG signal was positively related to the amount of force produced by the muscle; hence, it could provide a general guideline as to the difficulty of the exercise [45]. Loads of $45-50 \%$ of one repetition at maximum effort (1RM) have been shown to increase strength in previously untrained individuals [46-48]. The addition of the suspension training system could effectively increase the anterior and posterior core muscle activation from low level to very high level, thereby improving core training exercises in a similar body position for strengthening purposes. Furthermore, bridge exercises with suspension were ideal transitional training for athletes to improve strengthening exercises on an unstable base of support. Literature findings indicated that the RA activation level when performing dynamic exercises, such as push-up, in suspension was very high $(88 \%)$, but it was moderate $(24 \%)$ when such exercises were performed on the floor [49]. The isometric nature of suspended bridge exercises could fulfill the prerequisite of high RA activation in advanced dynamic strengthening exercises. The implicit instability of suspension training could also be utilized to train core-stabilizing musculature, and its specificity could effectively mimic the loads of particular athletes such as swimmers [11]. 


\section{Practical Applications and Study Limitations}

This study found that the RA, RF, TES, LM, and BF had higher muscle activities in

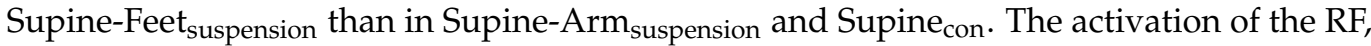
TES, and BF was higher under Supine-Arm suspension as compared with Supine $_{\text {con }}$. SupineFeet $_{\text {suspension }}$ elicited significantly lower muscle activity for GM when compared with Supine-Arm suspension $_{\text {and }}$ Supine $_{\text {con }}$. Therefore, if the target exercise muscle groups were

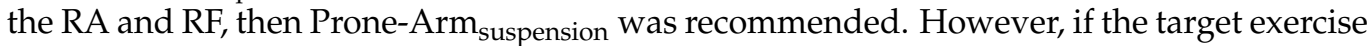

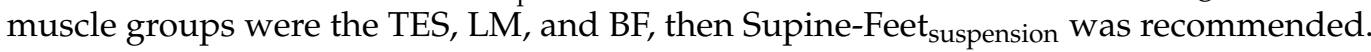
Such findings might be important for health professionals or strength and conditioning coaches to confirm the use of placing different body parts on suspension straps for core stability improvement or specific muscular training.

The acute responses of core muscle activity during bridge exercises were identified in this study. In a more practical situation, the change of muscle activity in prolonged bridge exercises may be another research area because some people may perform bridge exercises for several minutes.

Author Contributions: Conceptualization, J.T.C.L.; methodology, J.T.C.L.; software, J.T.C.L.; validation, J.T.C.L. and D.P.W.; formal analysis, J.T.C.L.; investigation, J.T.C.L.; resources, J.T.C.L.; data curation, J.T.C.L.; writing-original draft preparation, J.T.C.L. and F.K.C.K.; writing- J.T.C.L. and D.P.W.; editing, J.T.C.L. and D.P.W.; visualization, I.M.K.H. and D.P.W.; supervision, J.T.C.L. and I.M.K.H.; project administration, J.T.C.L. and I.M.K.H.; funding acquisition, J.T.C.L., I.M.K.H. and D.P.W. All authors have read and agreed to the published version of the manuscript.

Funding: THEi Seed Grant Scheme, Project reference number: 1314107.

Institutional Review Board Statement: Research Ethics Committee of the Technology and Higher Educational Institution (Reference No: THEi-ILO/5/1/8).

Informed Consent Statement: Informed consent was obtained from all subjects involved in the study.

Data Availability Statement: The data presented in this study are available on request from the corresponding author.

Conflicts of Interest: The authors declare no conflict of interest.

\section{References}

1. Kibler, W.B.; Press, J.; Sciascia, A. The role of core stability in athletic function. Sports Med. 2006, 36, 189-198. [CrossRef] [PubMed]

2. Snarr, R.L.; Esco, M.R. Electromyographical comparison of plank variations performed with and without instability devices. J. Strength Cond. Res. 2014, 28, 3298-3305. [CrossRef] [PubMed]

3. Hirashima, M.; Kadota, H.; Sakurai, S.; Kudo, K.; Ohtsuki, T. Sequential muscle activity and its functional role in the upper extremity and trunk during overarm throwing. J. Sports Sci. 2002, 20, 301-310. [CrossRef] [PubMed]

4. $\quad$ Escamilla, R.F.; Lewis, C.; Bell, D.; Bramblet, G.; Daffron, J.; Lambert, S.; Pecson, A.; Imamura, R.; Paulos, L.; Andrews, J.R. Core muscle activation during Swiss ball and traditional abdominal exercises. J. Orthop. Sports Phys. Ther. 2010, 40, 265-276. [CrossRef] [PubMed]

5. Wang, X.Q.; Zheng, J.J.; Yu, Z.W.; Bi, X.; Lou, S.J.; Liu, J.; Cai, B.; Hua, Y.H.; Wu, M.; Wei, M.L.; et al. A meta-analysis of core stability exercise versus general exercise for chronic low back pain. PLoS ONE 2012, 7, e52082. [CrossRef]

6. Leetun, D.T.; Ireland, M.L.; Willson, J.D.; Ballantyne, B.T.; Davis, I.M. Core stability measures as risk factors for lower extremity injury in athletes. Med. Sci. Sports Exerc. 2004, 36, 926-934. [CrossRef] [PubMed]

7. Nelson, N. Diaphragmatic Breathing: The Foundation of Core Stability. Strength Cond. J. 2012, 34, 34-40. [CrossRef]

8. Bird, S.P.; Stuart, W. Integrating Balance and Postural Stability Exercises into the Functional Warm-up for Youth Athletes. Strength Cond. J. 2012, 34, 73-79. [CrossRef]

9. Magnus, C.R.; Farthing, J.P. Greater bilateral deficit in leg press than in handgrip exercise might be linked to differences in postural stability requirements. Appl. Physiol. Nutr. Metab. 2008, 33, 1132-1139. [CrossRef]

10. Ekstrom, R.A.; Donatelli, R.A.; Carp, K.C. Electromyographic analysis of core trunk, hip, and thigh muscles during 9 rehabilitation exercises. J. Orthop. Sports Phys. Ther. 2007, 37, 754-762. [CrossRef] [PubMed]

11. Atkins, S.J.; Bentley, I.; Brooks, D.; Burrows, M.P.; Hurst, H.T.; Sinclair, J.K. Electromyographic response of global abdominal stabilizers in response to stable- and unstable-base isometric exercise. J. Strength Cond. Res. 2015, 29, 1609-1615. [CrossRef] [PubMed]

12. Behm, D.; Colado, J.C. The effectiveness of resistance training using unstable surfaces and devices for rehabilitation. Int. J. Sports Phys. Ther. 2012, 7, 226-241. [PubMed] 
13. Marshall, P.W.; Desai, I. Electromyographic analysis of upper body, lower body, and abdominal muscles during advanced Swiss ball exercises. J. Strength Cond. Res. 2010, 24, 1537-1545. [CrossRef] [PubMed]

14. Wirth, B.; Zurfluh, S.; Muller, R. Acute effects of whole-body vibration on trunk muscles in young healthy adults. J. Electromyogr. Kinesiol. 2011, 21, 450-457. [CrossRef]

15. Byrne, J.M.; Bishop, N.S.; Caines, A.M.; Crane, K.A.; Feaver, A.M.; Pearcey, G.E. Effect of using a suspension training system on muscle activation during the performance of a front plank exercise. J. Strength Cond. Res. 2014, 28, 3049-3055. [CrossRef]

16. Tinto, A.; Campanella, M.; Fasano, M. Core strengthening and synchronized swimming: TRX(R) suspension training in young female athletes. J. Sports Med. Phys. Fit. 2017, 57, 744-751. [CrossRef]

17. Ma, X.; Sun, W.; Lu, A.; Ma, P.; Jiang, C. The improvement of suspension training for trunk muscle power in Sanda athletes. J. Exerc. Sci. Fit. 2017, 15, 81-88. [CrossRef]

18. Andrejeva, J.; Kasradze, M.; Mockiene, A.; Radziuviene, R.; Zakharchuk, J. Impact of TRX suspension training on patients' balance, coordination and quality of life after traumatic brain injury. Georgian Med. News 2020, 298, 119-122.

19. Gaedtke, A.; Morat, T. TRX Suspension Training: A New Functional Training Approach for Older Adults-Development, Training Control and Feasibility. Int. J. Exerc. Sci. 2015, 8, 224-233.

20. Harris, S.; Ruffin, E.; Brewer, W.; Ortiz, A. Muscle activation patterns during suspension training exercises. Int. J. Sports Phys. Ther. 2017, 12, 42-52. [CrossRef]

21. Aguilera-Castells, J.; Busca, B.; Fort-Vanmeerhaeghe, A.; Montalvo, A.M.; Pena, J. Muscle activation in suspension training: A systematic review. Sports Biomech. 2020, 19, 55-75. [CrossRef] [PubMed]

22. Calatayud, J.; Casana, J.; Martin, F.; Jakobsen, M.D.; Colado, J.C.; Gargallo, P.; Juesas, A.; Munoz, V.; Andersen, L.L. Trunk muscle activity during different variations of the supine plank exercise. Musculoskelet. Sci. Pract. 2017, 28, 54-58. [CrossRef] [PubMed]

23. Lee, J.; Jeong, K.; Lee, H.; Shin, J.; Choi, J.; Kang, S.; Lee, B.-H. Comparison of three different surface plank exercises on core muscle activity. Phys. Ther. Rehabil. Sci. 2016, 5, 29-33. [CrossRef]

24. Schoffstall, J.E.; Titcomb, D.A.; Kilbourne, B.F. Electromyographic response of the abdominal musculature to varying abdominal exercises. J. Strength Cond. Res. 2010, 24, 3422-3426. [CrossRef] [PubMed]

25. Jung, J.; Yu, J.; Kang, H. Differences in Trunk Muscle Activities and Ratios between Unstable Supine and Prone Bridging Exercises in Individuals with Low Back Pain. J. Phys. Ther. Sci. 2012, 24, 889-892. [CrossRef]

26. Lehman, G.J.; Hoda, W.; Oliver, S. Trunk muscle activity during bridging exercises on and off a Swiss ball. Chiropr. Osteopathy 2005, 13, 14. [CrossRef] [PubMed]

27. Stevens, V.K.; Bouche, K.G.; Mahieu, N.N.; Coorevits, P.L.; Vanderstraeten, G.G.; Danneels, L.A. Trunk muscle activity in healthy subjects during bridging stabilization exercises. BMC Musculoskelet. Disord. 2006, 7, 75. [CrossRef]

28. Drysdale, C.L.; Earl, J.E.; Hertel, J. Surface Electromyographic Activity of the Abdominal Muscles During Pelvic-Tilt and Abdominal-Hollowing Exercises. J. Athl. Train. 2004, 39, 32-36. [PubMed]

29. Ershad, N.; Kahrizi, S.; Abadi, M.F.; Zadeh, S.F. Evaluation of trunk muscle activity in chronic low back pain patients and healthy individuals during holding loads. J. Back Musculoskelet. Rehabil. 2009, 22, 165-172. [CrossRef] [PubMed]

30. World Medical Association. Declaration of Helsinki: Ethical principles for medical research involving human subjects. J. Am. Coll. Dent. 2014, 81, 14-18.

31. Danneels, L.A.; Coorevits, P.L.; Cools, A.M.; Vanderstraeten, G.G.; Cambier, D.C.; Witvrouw, E.E.; De, C.H. Differences in electromyographic activity in the multifidus muscle and the iliocostalis lumborum between healthy subjects and patients with sub-acute and chronic low back pain. Eur. Spine J. 2002, 11, 13-19. [CrossRef]

32. Hibbs, A.E.; Thompson, K.G.; French, D.N.; Hodgson, D.; Spears, I.R. Peak and average rectified EMG measures: Which method of data reduction should be used for assessing core training exercises? J. Electromyogr. Kinesiol. 2011, 21, 102-111. [CrossRef] [PubMed]

33. Cram, J.R. Introduction to Surface Electromyography; Aspen Publishers: Gaithersburg, MD, USA, 1998.

34. Norwood, J.T.; Anderson, G.S.; Gaetz, M.B.; Twist, P.W. Electromyographic activity of the trunk stabilizers during stable and unstable bench press. J. Strength Cond. Res. 2007, 21, 343-347. [CrossRef] [PubMed]

35. Beith, I.D.; Synnott, R.E.; Newman, S.A. Abdominal muscle activity during the abdominal hollowing manoeuvre in the four point kneeling and prone positions. Man. Ther. 2001, 6, 82-87. [CrossRef] [PubMed]

36. Westing, S.H.; Cresswell, A.G.; Thorstensson, A. Muscle activation during maximal voluntary eccentric and concentric knee extension. Eur. J. Appl. Physiol. Occup. Physiol. 1991, 62, 104-108. [CrossRef]

37. Kendall, F.P. Muscles, Testing and Function: With Posture and Pain, 5th ed.; Lippincott Williams \& Wilkins: Baltimore, MD, USA, 2005.

38. Arokoski, J.P.; Kankaanpaa, M.; Valta, T.; Juvonen, I.; Partanen, J.; Taimela, S.; Lindgren, K.A.; Airaksinen, O. Back and hip extensor muscle function during therapeutic exercises. Arch. Phys. Med. Rehabil. 1999, 80, 842-850. [CrossRef]

39. Digiovine, N.M.; Jobe, F.W.; Pink, M.; Perry, J. An electromyographic analysis of the upper extremity in pitching. J. Shoulder Elb. Surg. 1992, 1, 15-25. [CrossRef]

40. Koo, T.K.; Li, M.Y. A Guideline of Selecting and Reporting Intraclass Correlation Coefficients for Reliability Research. J. Chiropr. Med. 2016, 15, 155-163. [CrossRef] [PubMed]

41. Portney, L. Foundations of Clinical Research Applications to Practice, 3rd ed.; Pearson/Prentice Hall: Upper Saddle River, NJ, USA, 2015. 
42. Cohen, J. Statistical Power Analysis for the Behavioral Sciences, 2nd ed.; L. Erlbaum Associates: Hillsdale, NJ, USA, 1988.

43. Imai, A.; Kaneoka, K.; Okubo, Y.; Shiina, I.; Tatsumura, M.; Izumi, S.; Shiraki, H. Trunk muscle activity during lumbar stabilization exercises on both a stable and unstable surface. J. Orthop. Sports Phys. Ther. 2010, 40, 369-375. [CrossRef] [PubMed]

44. Mathiassen, S.E.; Winkel, J.; Hägg, G.M. Normalization of surface EMG amplitude from the upper trapezius muscle in ergonomic studies-A review. J. Electromyogr. Kinesiol. 1995, 5, 197-226. [CrossRef]

45. DeLuca, C.J. The use of surface electromyography in biomechanics. J. Appl. Biomech. 1997, 13, 135-163. [CrossRef]

46. Anderson, T.; Kearney, J.T. Effects of three resistance training programs on muscular strength and absolute and relative endurance. Res. Q. Exerc. Sport 1982, 53, 1-7. [CrossRef] [PubMed]

47. Gettman, L.R.; Ayres, J.J.; Pollock, M.L.; Jackson, A. The effect of circuit weight training on strength, cardiorespiratory function, and body composition of adult men. Med. Sci. Sports 1978, 10, 171-176. [PubMed]

48. Sale, D.G.; Jacobs, I.; MacDougall, J.D.; Garner, S. Comparison of two regimens of concurrent strength and endurance training. Med. Sci. Sports Exerc. 1990, 22, 348-356. [CrossRef] [PubMed]

49. Calatayud, J.; Borreani, S.; Colado, J.C.; Martin, F.F.; Rogers, M.E.; Behm, D.G.; Andersen, L.L. Muscle Activation during Push-Ups with Different Suspension Training Systems. J. Sports Sci. Med. 2014, 13, 502-510. [PubMed] 